\title{
Ascensão da China e transição de poder: conflito entre a teoria neorrealista e a neoliberal ${ }^{1}$
}

The rise of China and power transition: conflict among the neorealist and the neoliberal theories

\author{
Augusto César Dall'Agnol²
}

\section{RESUMO}

O objetivo deste artigo é comparar duas abordagens teóricas sobre a ascensão da China e a possível transição de poder decorrente da mesma, especificamente as perspectivas de Joseph S. Nye e John J. Mearsheimer. Expor-se-á, portanto, as distintas abordagens em relação a ascensão chinesa e aos reajustes de poder no sistema internacional.

Palavras-chave: neorrealismo; neoliberalismo; ascensão da China.

\begin{abstract}
This article focuses on the rise of China and the power transition through the two main approaches that the international relations theories have about this subject, specifically from Joseph S. Nye and John J. Mearsheimer. Finally, this paper shows the diferents approaches about the rise of China and the rearrange of power in the international system.
\end{abstract}

Keywords: neorealism, neoliberalism, China's rise.

\section{INTRODUÇÃo}

Ao abordar a ascensão chinesa, elegeu-se um teórico como representante de cada corrente: Joseph S. Nye e John J. Mearsheimer. O primeiro, junto com Robert Keohane, é um dos expoentes do neoliberalismo e da ideia de interdependência complexa. 0 segundo, é um dos principais neorrealistas da atualidade; entretanto, diferentemente de

\footnotetext{
${ }^{1} \mathrm{O}$ presente artigo foi submetido e aprovado no $\mathrm{V}$ Encontro Estudantil Regional de Relações Internacionais, sediado em Santa Cruz do Sul em setembro de 2014; entretanto, não foi publicado nos anais do evento pela não apresentação do mesmo devido à enfermidade do autor.

${ }^{2}$ Graduando em Relações Internacionais pela Universidade Federal de Santa Maria (UFSM), pesquisadormembro do Núcleo de Pesquisa em Relações Internacionais de Santa Maria (PRISMA) e membro do Comitê Editorial da Revista InterAção (ISSN 2357-7975). Santa Maria, Brasil. E-mail: a.agnol@gmail.com 
Waltz, Mearsheimer defende um realismo ofensivo, que será abordado ao longo deste trabalho. Ressalta-se, entretanto, que elencar um único autor de uma corrente teórica não significa considerar o mesmo o mais importante, nem entender que a corrente teórica seja circunscrita às ideias do pensador. Cada autor supracitado está inserido em um tronco teórico mais amplo e complexo. Por fim, ressalta-se que o pensamento de cada teórico é bem mais amplo e que as ideias abordadas neste trabalho, cujo objetivo é mostrar o embate entre a teoria neoliberal e a neorrealista, no que diz respeito ao reajuste de poder e da ascensão da China.

\section{Joseph S. Nye e o Neoliberalismo}

Na visão dos realistas, ao exemplo de John J. Mearsheimer, conhecer a distribuição de recursos poder seria conhecer a estrutura da política mundial e, uma vez conhecida a sua estrutura, poderia-se prever certos padrões de comportamentos dos Estados. Neste sentido, sabe-se que a visão tradicional defendia que o poder militar dominava as outras formas de poder, e que os Estados com as maiores capacidades militares acabavam por controlar os assuntos mundiais; entretanto, para Keohane e Nye (1989, p. 11) afirmam que os recursos que produzem capacidades de poder haviam se transformado em algo mais complexo.

Já no início do capítulo 2, Realism and Complex Interdependence, Keohane e Nye (Idem, p. 23, tradução nossa), apontam que "nesse capítulo, nós vamos construir um outro tipo ideal, o oposto ao realismo. Nós o chamamos de interdependência complexa." Conceituam, assim, os autores, a interdependência: "na política mundial, a interdependência refere-se a situações caracterizadas por efeitos recíprocos entres países ou entre atores em diferentes países". (Ibidem, p. 8, tradução nossa)

A interdependência complexa, por sua vez, apresenta três características fundamentais:

a) multiplos canais conectam sociedades, incluindo laços informais entre elites governamentais, bem como acordos informais entre escritórios estrangeiros; b) a agenda das relações interestatais consiste em múltiplas questões que não são arranjadas de uma forma clara ou hierárquica; c) a força militar não é utilizada por governos contra outro governos dentro da região em que a interdependência complexa prevalece. (Ibidem, p. 25, tradução nossa) 
O aumento da integração e da interdependência econômica e institucional no sistema internacional aumenta, portanto, as possibilidades de cooperação entre Estados e a diminuição das tendências bélicas. Ressalta-se, porém, que os autores não afirmam que a interdependência teria como resultado necessário a redução de conflitos no nível internacional (Ibidem, p. 10).

Em Power and Interdependence, os autores procuram desenvolver uma teoria que se contraponha ao realismo e que se apresente como maneira alternativa de se entender a política mundial. Imaginam, pois, um sistema internacional no qual não apenas a estrutura, tal qual era concebida pelos teóricos tradicionais, fosse relevante, mas também o processo de barganha, meio como essas capacidades são utilizadas, seria fundamental para a sua compreensão. Apontam, assim, Keohane e Nye (Ibidem, p. 225, tradução nossa), sobre o processo de barganha: "para prever e entender os resultados, devemos dar igual atenção ao processo de barganha, meio pelo qual os recursos de poder são convertidos em influência efetiva sobre os resultados". Neste sentido, Nye (2012) ressalta que, ainda que a China tenha um longo caminho para igualar os recursos de poder dos Estados Unidos, há outros obstáculos que barram o seu desenvolvimento, a exemplo do soft power e da barganha.

O crescimento econômico chinês trará, de fato, a China para mais próximo dos Estados Unidos em recursos de poder; entretanto, não significa que a China irá ultrapassar os Estados Unidos como o país mais poderoso. Conforme aponta Nye (2010, p. 10, tradução nossa), projeções baseadas no Produto Interno Bruto crescem sozinhas, são unidimensionais e "ignoram as vantagens militares e o soft power dos Estados Unidos, assim como ignoram as desvantagens geopolíticas da China na balança de poder da Ásia".

A interdependência afeta as políticas mundiais e o comportamento dos Estados. Keohane e Nye (1989, p. 5), entretanto, ressaltam que ações governamentais também influenciam padrões de interdependência. Ou seja, ao criar e aceitar procedimentos, regras, ou instituições para certos tipos de atividades, os governos regulam e controlam as relações transnacionais e interestatais. Os Estados Unidos estão, então, bem posicionados para se beneficiarem das suas alianças - Japão, Índia, Austrália, União Europeia - regras e instituições, desde que adotem estratégias inteligentes, uma vez que 
eles e seus aliados compartilham redes sociais e governamentais que criam oportunidades para a cooperação.

Também observam os autores acerca da cooperação que:

[...] em um mundo de múltiplas questões ligadas imperfeitamente, em que coalisões são formadas transnacionalmente e transgovernamentalmente, o papel potencial das instituições internacionais é crescente. Em particular, elas ajudam a definir a agenda internacional e agir como catalizador para formação de coalisões e arenas para iniciativas políticas entre Estados (1989, p. 35, tradução nossa).

A integração da China na economia global e sua participação cada vez mais ativa em organizações internacionais traz, portanto, ganhos absolutos, o que reduz as ameaças de uma China beligerante e aumenta as possibilidades de uma ascensão pacífica. Joseph S. Nye (2010, p. 3) aponta, ainda, que o sistema internacional atual lembra um complexo jogo de xadrez tridimensional. No topo do tabuleiro, o poder militar é fortemente unipolar, e os Estados Unidos tendem a se manter no topo por um bom tempo tempo. No meio do tabuleiro, o poder econômico vem sendo multipolar por mais de uma década, com os Estados Unidos, Europa, Japão e China. A base do tabuleiro é a região das relações transnacionais, onde o poder é densamente difuso entre atores não-estatais, investidores, terroristas, hackers, pandemias e mudanças climáticas.

Ao discorrer acerca da ascensão da China e do futuro do poder dos Estados Unidos - discussão que estaria em todos os níveis desse tabuleiro tridimensional - Nye aborda duas ideias de declínio diferentes: absolute decline, no sentido de decaimento, e relative decline, referente ao aumento de recursos e de poder dos outros Estados.

Hoje, alguns afirmam confiantemente que o século XXI verá a China substituir os Estados Unidos como o Estado que lidera o mundo, enquanto outros argumentam com igual confiança que os século XXI será o século dos Estados Unidos. Entretanto, imprevistos muitas vezes confundem tais projeções. Sempre há uma variedade de possibilidades futuras, e não somente uma (NYE, 2010, p. 10, tradução nossa).

Reforça-se, a fim de encerrar esta seção, que na visão de Nye, a interdependência complexa possui três características principais: a existência de canais múltiplos que 
conectam as sociedades; a ausência de uma hierarquia fixa de temas na agenda das relações interestatais e, por fim, a não utilização da força como instrumento de política nesse contexto de interdependência complexa. Para Keohane e Nye (1989, p. 30), Estados militarmente fortes vão achar mais difícil de usar o seu domínio global para controlar resulados em questões que eles são fracos. Neste sentido, a ascensão da China, tida muitas vezes como país aspirante ao papel que hoje se atribui aos norteamericanos, faz-se necessária nas discussões globais de sucessão hegemônica e reorganização do equilíbrio de poder. Embora Nye reconheça o potencial do crescimento chinês, o autor ressalta que as projeções se baseiam fortemente no crescimento econômico do país, mas não levam em consideração outras esferas, como a superioridade militar dos Estados Unidos e, principalmente, a deficiência dos chineses em termos de soft power.

Nye aponta, ainda, que a ascensão da China pode criar instabilidade, "mas esse é um problema com precedentes, e a história sugere como políticas podem afetar os resultados" (2012, p. 216, tradução nossa). 0 autor afirma então, que ao se olhar para a história, vê-se que os Estados Unidos têm duas características que os distinguem das grandes potências do passado - contrariando, portanto, a ideia de John J. Measheimer que será exposta na próxima seção: o poder americano é baseado em alianças, e não em colônias; e está associado a uma ideologia flexível. Portanto, essas alianças podem proporcionar um núcleo de relações e valores que os Estados Unidos podem retomar mesmo com seu declínio relativo.

Joseph S. Nye (2010, p. 11, tradução nossa) aponta, por fim, que descrever a transição de poder no século XXI como um caso tradicional de declínio hegemônico é impreciso e "pode levar a perigosas implicações políticas se isso encorajar a China a engajar em uma política ofensiva, ou os Estados Unidos reagirem com muita força devido ao medo da crescente ascensão chinesa".

De acordo com o autor, percebe-se que o poder tradicional, orientado basicamente pelas capacidades militares e econômicas, continuaria não sendo capaz de lidar com novos temas, a exemplo da mudança climática, instabilidades financeiras e emissão de gás carbônico. Mais do que nunca, portanto, os Estados deveriam se orientar com base na lógica de poder com os outros (power with), e não com a noção de poder 
sobre os outros (power over), uma vez que os problemas do século XXI afetam a todos e, tanto a China, quanto os Estados Unidos, não podem resolver estes problemas sozinhos. Expor-se-á, no próximo capítulo, o que o autor definiu como o oposto da interdependência complexa, sob a ótica de John J. Mearsheimer.

\section{John J. Mearsheimer e o Neorrealismo Ofensivo}

John J. Mearsheimer, ao discorrer sobre o futuro do sistema internacional e da ascensão da China, vale-se da corrente epistemológica do tradicionalismo, que é, também, fundamento das teorias do Realismo Clássico, de Hans Morgenthau, por exemplo. Sua linha de pensamento baseia-se, então, em premissas filosóficas e na interpretação da história. Isso fica evidente quando Mearsheimer (2006, p. 160) afirma que, para entender o comportamento esperado da China, a teoria precisa soar de forma lógica e precisa valer-se dos comportamentos passados das ascensões das grandes potências.

Ao definir o sistema internacional, Mearsheimer (Idem, p. 160, tradução nossa) aponta que o mesmo possui três características fundamentais:

[...] primeira, os Estados são os principais atores e operam em anarquia, o que significa, simplesmente, que não há uma autoridade mais forte acima deles. Segunda, todas as grandes potências tem alguma capacitade militar ofensiva, o que significa que elas têm meios para ferir umas as outras. Terceira, nenhum Estado pode saber a intenção de outro com certeza, especialmente suas futuras intenções.

Percebe-se, então, que neoliberais e neorrealistas convergem quanto à natureza da anarquia, no sentido da ausência de uma autoridade acima das soberanias dos Estados. Com isso, o objetivo mais importante de cada Estado, segundo Mearsheimer e o realismo ofensivo, é sobreviver. Ou seja, um Estado não pode ter qualquer outro objetivo se, ao menos, não sobreviver. Neste sentido, a estrutura básica do sistema internacional, segundo John J. Mearsheimer (Ibidem, p. 160, tradução nossa) força os Estados a se "preocuparem com sua segurança e competirem entre eles por poder [...] e a última meta de toda a grande potência é maximizar sua quota de poder mundial e eventualmente dominar o sistema". Além disso, para o autor, as grandes potências não ambicionam somente ser o Estado mais forte e poderoso do sistema, mas ser hegemônico, isto é, a 
única grande potência do sistema. Mearsheimer afirma, entretanto, que é praticamente impossível para um Estado alcançar o status de hegemonia global devido a dificuldade de projetar e sustentar poder em territórios ao redor do mundo, e que "a melhor posição que um Estado pode aspirar a ser é ser um hegêmona regional e, assim, dominar a sua região geográfica" (Ibidem, p. 160).

De acordo com o neorrealista, sabendo que, por ser muito arriscado, a hegemonia global é praticamente impossível, quando uma potência atinge o status de hegêmona regional, seu principal interesse passa a ser impedir o surgimento de hegêmonas em outras regiões. Isso fica claro quando Mearsheimer (2013, p. 83, tradução nossa) afirma que os Estados que alcançam a hegemonia regional tem um desejo maior: "eles buscam prevenir outras grandes potências em outras regiões geográficas de duplicarem seus tamanhos. Hegêmonas regionais, em outras palavras, não querem competidores". Ou seja, a hipótese mais ameaçadora para os Estados Unidos, no horizonte próximo, é a possível ascensão da China a um patamar de hegêmona no nordeste da Ásia, tornando difícil ou impossível que uma balança de poder regional pudesse efetivamente contê-la.

Mearsheimer destaca, neste sentido, dois mecanismos diplomáticos utilizados pelos Estados ao enfrentarem o crescimento acelerado de um terceiro: o balancing e o buck-passing. 0 balancing é quando um Estado tenta neutralizar o crescimento de uma potência hegemônica regional por meio da constituição de alianças com outros Estados. Ou seja, o balancing aconteceria caso os vizinhos da China e os Estados Unidos se aliassem a fim de conter a ascensão chinesa. Já o buck-passing, por sua vez, é quando um Estado prefere delegar a um outro Estado a responsabilidade de neutralizar o avanço de uma eventual potência hegemônica. Ou seja, o buck-passing, seria se os Estados Unidos se afastassem do nordeste da Ásia e deixassem que própria competição regional impedisse o surgimento de um hegêmona. Segundo Diniz (2006, p. 514) essa atitude de "balanceador externo lhes permitiria transferir (buckpass) os custos e riscos do balanceamento para as potências regionais e, no mínimo, preservar mais facilmente seu poder concreto e potencial". Referindo-se ao balancing e ao buck-passing, Mearsheimer (2001, p. 42, tradução nossa) afirma que:

se um hegêmona potencial emerge, talvez as outras grandes potências daquela região possam contê-la com suas próprias forças, permitindo 
que o hegêmona distante permaneça em segurança e fora à margem do conflito. Claro que se as potências locais não conseguirem fazer o trabalho, o hegêmona distante tomaria as medidas apropriadas para lidar com o Estado em ascensão. Os Estados Unidos assumiu essa responsabilidade em quatro ocasiões distintas no século XXI, e, por isso, é normalmente referido como um offshore balancer.

As quatro ocasiões em que os Estados Unidos atuaram como offshore balancer, ou balanceador externo, as quais Mearsheimer se refere, são: o Império Alemão (19001918), o Império Japonês (1931-1945), a Alemanha Nazista (1933-1945) e a União Soviética durante a Guerra Fria (1945-1989). Os Estados Unidos agiram, então, em cada caso, desfazendo e desmantelando as aspirações de hegemonia que partiam de outras potências.

Com isso, Mearsheimer vale-se do conceito realista de "dilema de segurança", ou seja, na medida em que um Estado adota políticas para melhorar sua segurança, ele acaba, normalmente, reduzindo a segurança dos outros Estados. Afirma o autor, então, que "é difícil para um Estado aumentar suas próprias chances de sobrevivência sem ameaçar a sobrevivência de outro Estado" (Idem, p. 36, tradução nossa). Neste sentido, ao observarem o crescimento chinês, os países asiáticos, Índia, Japão, Singapura, Coréia do Sul, Rússia e Vietnã, por exemplo, iriam valer-se de mecanismos de balancing ou buckpassing a fim de conter um hegêmona regional.

Percebe-se, com isso, que na visão de John J. Mearsheimer a ascensão da China está associada à hegemonia regional da China do nordeste da Ásia, e esta dependeria do afastamento dos Estados Unidos da região. Para afirmar seu argumento, Mearsheimer faz referência ao momento em que os Estados Unidos trabalhavam na conquista da hegemonia regional ao mencionar a Doutrina Monroe, que deixava a Europa de fora dos assuntos americanos. 0 comportamento da China não diferiria, portanto, para o autor, do comportamento dos Estados Unidos do século XIX , uma vez que uma China cada vez mais poderosa "provavelmente tentaria tirar os Estados Unidos da Ásia, muito semelhante à forma que os Estados Unidos tiraram as potências europeias do Hemisfério ocidental. (MEARSHEIMER, 2013, p. 83, tradução nossa)."

O discurso de Mearsheimer fica marcado, pois, pela ideia de power over, que contrasta com a de power with, conforme sugere Joseph S. Nye. Ou seja, para Conjuntura Global, Vol. 4, n. 1, jan./abr., 2015, pp. 102-112. 
Mearsheimer (2001, p. 29, tradução nossa) as grandes potências "estão sempre procurando oportunidade para ganhar poder sobre seus rivais", o que confere um forte caráter de neorrealismo ofensivo ao seu discurso. Ao discorrer acerca do comportamento dos Estados Unidos, Mearsheimer (2006, p. 162, tradução nossa) faz alusão ao modo como a política americana se guiou no último século:

está claro de acordo com o registro histórico de como os policymakers americanos vão reagir se a China tentar dominar a Ásia. Os Estados Unidos não toleram competidores páreos. Como demonstrado no século XXI, eles estão determinados a permanecer como o único hegêmona regional no mundo.

Conclui-se, então, conforme aponta Diniz (2006, p. 514 ), que, para o neorrealista, os Estados Unidos estariam na melhor situação concretamente alcançável na política internacional:

[...] sua principal preocupação seria apenas impedir o surgimento de um competidor, isto é, de algum outro hegêmona em alguma outra região relevante ou [...] deixar que as próprias dinâmicas competitivas regionais impeçam o surgimento de hegêmonas regionais.

Percebe-se, portanto, que Mearsheimer faz muito mais referências à história do que os realistas defensivos e procura elaborar suas contribuições teóricas em cima de fatos históricos. Os Estados Unidos deveriam intervir, por fim, apenas se a competição regional não fosse suficiente para impedir o surgimento de hegêmonas nas outras balanças de poder regionais.

\section{Considerações finais}

Percebe-se, entre as ideias dos autores, fortes premissas de suas correntes teóricas. Para os neorrealistas, os Estados buscam ganhos relativos e focam nas high politics, enquanto para os neoliberais os Estados buscam ganhos absolutos e focam nas low politics. Após as considerações acerca da ascensão da China sob esta ótica neo-neo, ressalta-se que é importante não cair na armadilha do idealismo e desconsiderar a dimensão do poder na política mundial. 
Enquanto a teoria neorrealista desenha o sistema internacional governado pela anarquia, e parte da percepção de que os únicos atores das relações internacionais são os Estados - que têm interesses próprios e competem por ganhos relativos de poder -, e agem racionalmente prezando pela sua sobrevivência tentando maximizar seu poder e defender suas agendas, frequentemente causando tensões e conflitos com outros atores do sistema, a teoria neolibera sustenta que o aumento dos vínculos econômicos e dos laços institucionais, aumenta as chances de cooperação e diminui as chances de conflito. Os neoliberais discordam da visão neorrealista, portanto, ao sugerir que além dos Estados, o sistema internacional ainda pode ter outros atores relevantes, como organizações internacionais, empresas ou até mesmo indivíduos.

Portanto, a perspectiva neoliberal sugere que a integração da China na economia global e sua crescente participação em organizações internacionais traz ganhos absolutos, reduzindo as ameaças de uma China beligerante e aumentando as possibilidades de uma ascensão pacífica. 0 debate teórico acerca da transição de poder e da ascensão da China está, pois, longe de esgotar-se. É difícil saber, por fim, até que ponto esses paradigmas serão capazes de enquadrar uma realidade global crescentemente complexa.

\section{REFERÊNCIAS}

DINIZ, Eugenio. Relacionamentos Multilaterais na Unipolaridade - Uma Discussão Teórica Realista. Rio de Janeiro: Contexto Internacional, vol. 28, n. 02, jul./dez. 2006, p. 505-565.

KEOHANE, Robert 0; NYE, Joseph S. Power and Interdependence: World Politics in Transition. Boston: Little-Brown, 1989.

NYE, Joseph S. The Future of American Power: Dominance and Decline in Perspective. New York: Foreign Affairs, vol. 89, n. 06 p. 02-12, nov./dez. 2010. Disponível em: $<$ http://zip.net/byn5VG> Acesso em: 06 julho. 2014.

The Twenty-First Century Will Not Be a "Post-American" World. New York: International Studies Quarterly, vol. 56, p. 215-217, 2012. Disponível em: $<$ http://civicrm.wcfia.harvard.edu/sites/default/files/Nye 21st\%20cent.pdf $>$ Acess o em 17 julho. 2014.

MEARSHEIMER, John J. China's Unpeaceful Rise. Current History, vol. 105, nํ. 690 apr. 2006, pp. 160-162. 
Structural Realism. In: DUNNE, Tim; KURKI, Milja; SMITH, Steve (Org.) International Relations Theories: discipline and diversity. Oxford: Oxford University Press, 2013, p. 71-88.

. The Tragedy of Great Power Politics. New York: W.W. Norton and Company, 2001. 